\title{
Biomedical research productivity in Bangladesh (1996-2010): A comparison with low-income economy
}

\author{
Md. Anwarul Azim Majumder ${ }^{1}$, Sami F. Shaban ${ }^{2}$, Sayeeda Rahman ${ }^{3}$, Moslehuddin Ahmed $^{4}$
}

\begin{abstract}
${ }^{1,3}$ Lecturer, Department of Clinical Sciences, School of Medical Sciences, University of Bradford, West Yorkshire, Bradford, UK. ${ }^{2}$ Assistant Professor, Department of Medical Education, Faculty of Medicine and Health Sciences, UAE University, Al-Ain, UAE. ${ }^{4}$ Head and Professor, Department of Community Medicine, Uttara Adhunik Medical College, Dhaka, Bangladesh.
\end{abstract}

\section{To the Editor}

According to the World Bank, Bangladesh falls under the group of low-income economy countries (GDP per capita of $\$ 1,025$ or less). ${ }^{1}$ There are 36 countries in this group, one from Latin America, eight from Asia, and the rest from Africa. ${ }^{1}$ The countries in Asia are Afghanistan, Bangladesh, Cambodia, Kyrgyz Republic, Myanmar, Nepal, North Korea, and Tajikistan. During June 2012, a search of the 'SCImago Journal \& Country Rank' (SJR) was performed for publications in the field of 'medicine' in low-income economy countries from 1996-2010. ${ }^{2}$ The publications for each country were then normalized by total population, gross domestic product (GDP) and adult illiteracy rate. ${ }^{3,4}$ The SJR is a portal that includes the journals and country scientific indicators developed from the information contained in the Scopus ${ }^{\circledR}$ database (Elsevier $\mathrm{BV}){ }^{2}$ These indicators can be used to assess and analyze scientific domains. The platform has been developed by SCImago from the widely known algorithm Google PageRank ${ }^{\mathrm{TM}}{ }^{2}$ The aim of this paper is to analyze the biomedical publications of Bangladesh using SJR indicators and compare with the research productivity of other low income economy countries.

The findings of the present study showed that total number of papers published by all 36 low-income economy countries over 15 years totaled 22,053 , which is $0.34 \%$ of the total papers indexed by SJR in the same period. The average number of papers published by all the countries per year was 1470 . Kenya produced the highest number of papers, 3,153 , which is $14.3 \%$ of total papers generated by all low-income economy countries. Bangladesh and Nepal published second and fourth highest number of papers, which are $13.11 \%$ and $10.26 \%$ respectively. Bangladesh also ranked top among the countries of Asia region in world ranking for publications of papers in the field of medicine.

The total number of papers in the field of medicine published by the eight countries of the Asian region from 1996 to 2010 was 6,069 (Table 1), an average of 404 papers published per year. Bangladesh produced approximately half of the total papers $(47.7 \%)$ generated by lowincome economy countries in Asian region, with an average of 193 papers published per year. However, when the documents were normalized by the population (per million), GDP (per billion) and adult literacy, the position of Bangladesh lowered to third position in all categories (Table 1): 21, 47 and 39 respectively. Nepal had the highest and Cambodia had the second highest publications in all categories. The average normalized data of all categories showed that Nepal published 4.7 times and Cambodia generated 1.4 times of publications in comparison to Bangladesh. The trends of published papers of 5 countries with highest publications are shown in Figure 1. In 15 years, the relative increase in the number of publications in Bangladesh was $269 \%$ (444\% in the Asia region) and publications increased approximately by 3.69 -fold (5.44-fold in Asia region). The trend analysis of the data collected over 15 years showed that Bangladesh produced on average around 18.9 additional publications each year. Nepal also showed a similar slope (20.4), however with a slightly higher trend than Bangladesh.

A number of studies demonstrated the trends of biomedical publications and research productivity in Bangladesh $^{4-7}$ and other Asian countries; $;^{8-10}$ however, the present study is the first to compare the countries in the context of low-income economies using SJR indicators in deducing the status of research productivity. The SJR has many advantages: the best criterion is the simplicity of the web site use, the access is open, self citation is not included in the calculation and is updated daily. ${ }^{11}$ Analyzing the countries with similar economic statuses and further normalizing with other variables provides a true level playing field for authentic estimation and comparison of research productivity. Moreover, normalizing publications by different indicators is important because results may vary when using different normalizing indicators or no normalization at all. ${ }^{3}$ A study conducted by Rahman et al. ${ }^{8}$ identified low gross national income per capita, an insufficient number of physicians and inadequate public spending in the health sector as the causes for low research productivity in Asian countries. A recent study of biomedical publications of the SAARC countries

Correspondence: Dr. Md. Anwarul Azim Majumder, Lecturer, Department of Clinical Sciences, School of Medical Sciences, University of Bradford, Bradford BD7 1DP, West Yorkshire, UK. E-mail: a.a.majumder@bradford.ac.uk.

South East Asia Journal of Public Health 2012;2(1):70-72. (C) 2012 Majumder et al., publisher and licensee Public Health Foundation Bangladesh. This is an Open Access article which permits unrestricted non-commercial use, provided the original work is properly cited. 
Table 1: Total and adjusted biomedical publications and SJR indicators of Asian countries: 1996-2010

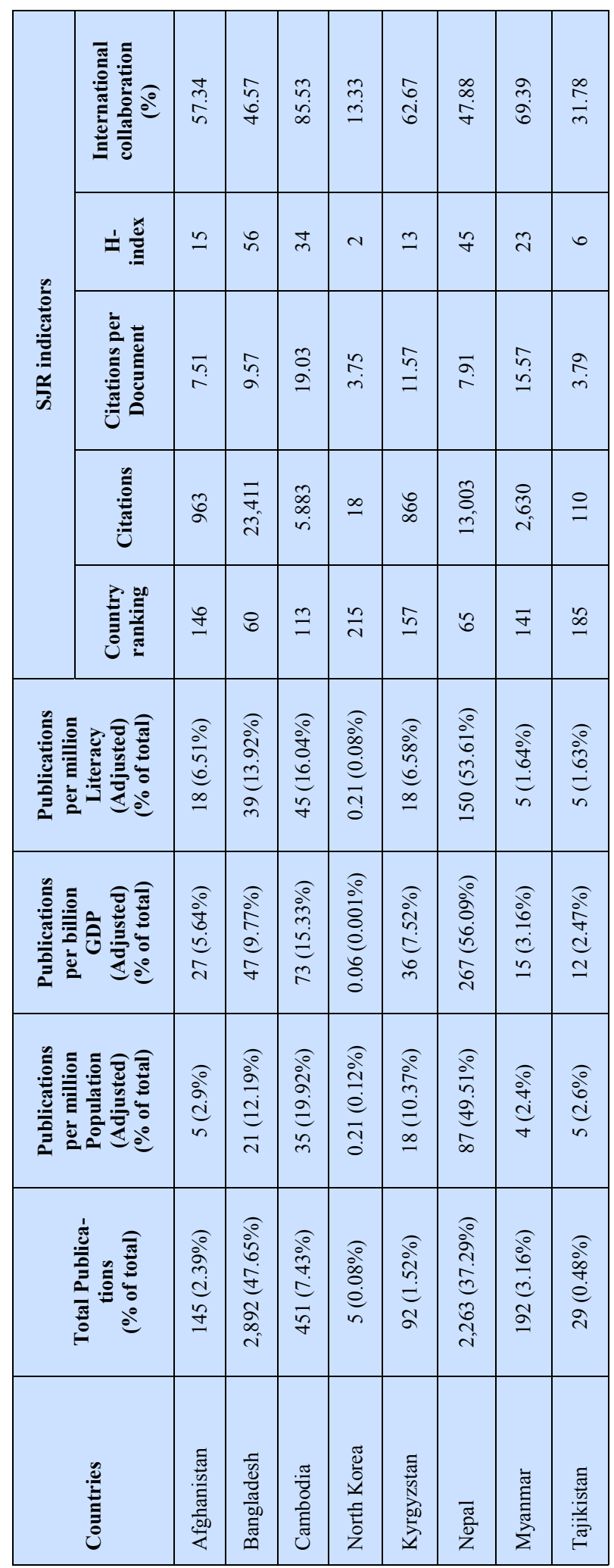

showed that Bangladesh published only $2 \%$ of the total publications from 1995-2009 and the trend is almost similar to that of present study when normalized with population, GDP and literacy: 20 (per million), 59 (per billion) and 38 respectively. ${ }^{4}$
The present study also revealed that Bangladesh had the highest citations and h-index among the Asian countries (Table 1); however the citation per document is lower than Nepal, Cambodia and Kyrgyzstan. The h-index indicates country's number of articles (h) that have received at least $\mathrm{h}$ citations and it quantifies both country's research productivity and impact. ${ }^{11}$ The papers published through international collaboration were much less in Bangladesh than most of the countries in the region. Under the subject area of 'medicine', the category of 'public health, environmental and occupational health' generated highest number of $606(21 \%)$ publications (h-index: 31, international collaborations: $59.4 \%$ ) in Bangladesh followed by 'infectious diseases' [publications: 224 (7.7\%), h-index: 23, international collaborations: $63.7 \%$ ], 'pediatrics, perinatology and child health' [publications: 212 (7.3\%), hindex: 31, international collaborations: 59\%] and 'obstetrics and gynecology' [publications: 209 (7.2\%), h -index: 14, international collaborations: $33.1 \%$ ].

One of the more important reasons for low citations per documents in Bangladesh may be due to lower numbers of papers published by international collaborations. A study conducted in Bangladesh ${ }^{5}$ (1990-1996) to quantify the volume of health related research identified that about two-thirds of the research were conducted by an international organization, ICDDRB (International Centre for Diarrheal Disease Research, Bangladesh). Research partnership with large multinational research groups have helped to attract more citations, ${ }^{6}$ which Bangladesh needs to explore to increase the visibility of research outputs in the international arena.

Low-income economy countries usually have minimum contribution to world research and scientific advances and these countries have become users of the research results generated by high income countries. ${ }^{12,13}$ The adjusted data of the present study showed that there is a significant problem in biomedical research in Bangladesh despite some major achievements in some of the SJR indicators (e.g. H-index).

Historically, medical research in Bangladesh does not receive high priority; for example, it has been demonstrated that the average number of research articles published by medical college attached tertiary teaching hospitals was less than one per year. ${ }^{5}$ There is an urgent need to boost the research activities by creating a 'research culture' in medical colleges, incorporating research methodology in undergraduate and postgraduate medical curricula, involving medical students in planning and conducting research projects and encouraging researchers to publish their research findings in international, indexed and peer-reviewed journals. ${ }^{4,12}$ Biomedical research is crucial for Bangladesh (and other low-income countries) to produce first-hand evidence to identify the extent and burden of health-related problems, identify priority areas, and to formulate a health policy to utilize the scarce resources available in healthcare sector. 


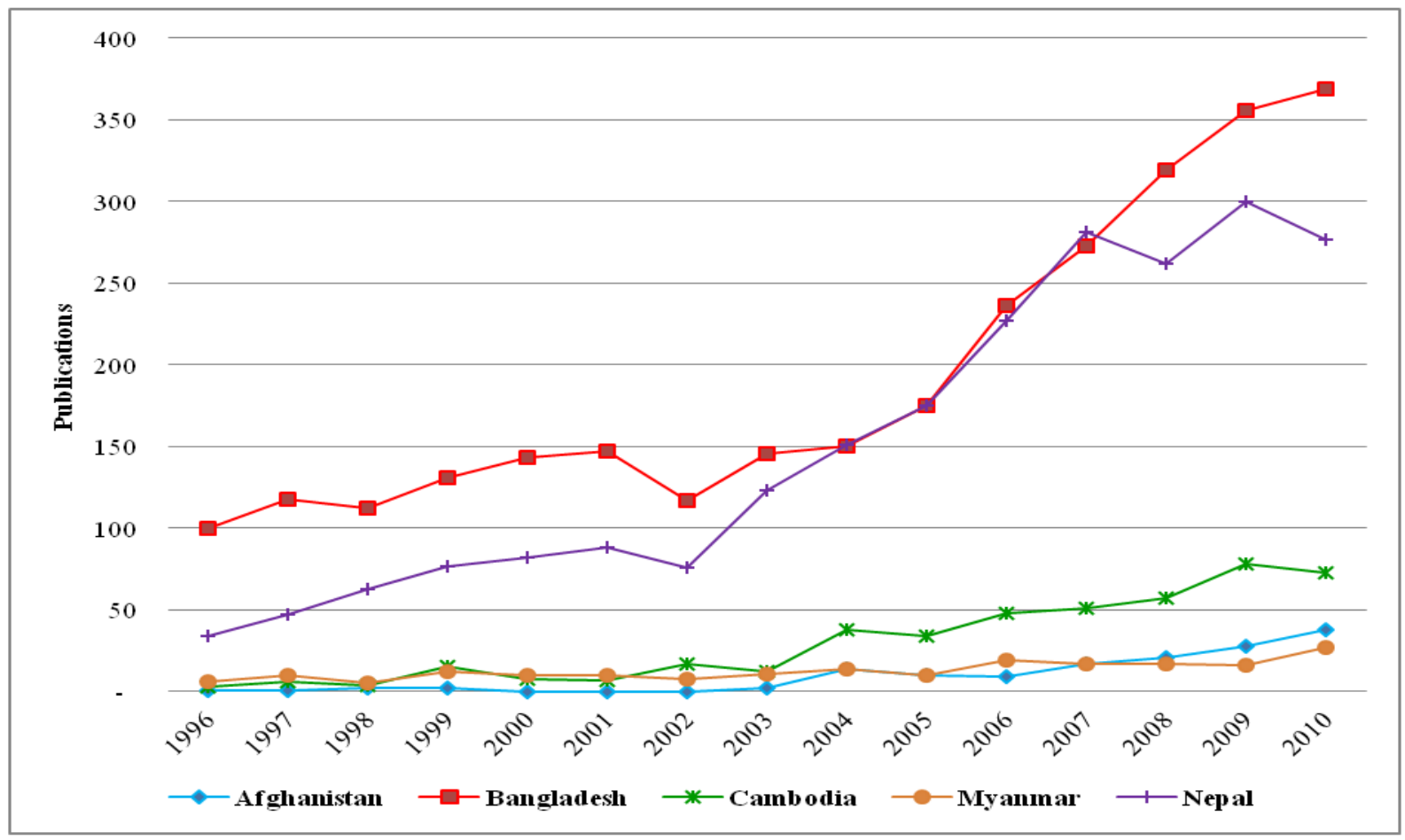

Figure 1: Trends of publications of 5 countries with highest publications

\section{References}

1. World Bank. How we Classify Countries. http:// data.worldbank.org/about/country-classifications (accessed 31 Dec 2011)

2. SCImago. (2007). SJR - SCImago Journal \& Country Rank. http://www.scimagojr.com (accessed July 2012)

3. Shaban SF, Abu-Zidan FM. A quantitative analysis of medical publications from Arab countries. Saudi Med J. 2003;24:294-6.

4. Majumder MAA, Rahman S, Shaban SF, N Rahman, Islam Z. A PubMed-Based Quantitative Analysis of Biomedical Publications in the SAARC Countries: 1985-2009. J Coll Physicians Surg Pak 2012;22:1-7.

5. Rahman M, Laz TH, Fukui T. Health related research in Bangladesh. J Epidemiol. 1999;9:235 -9 .

6. Mahbuba D, Rousseau R. Scientific Research in the Indian Subcontinent: Comparing Bangladesh, Pakistan and Sri Lanka with India. Paper presented at: 12th International Conference on Scientometrics and Informetrics; 14-17 July 2009; Rio de Janeiro, Brazil.
7. Mahbuba D, Rousseau R. Scientific Research in Bangladesh and a comparison with India and Pakistan. Korea J 2008; 5: 702-13.

8. Rahman M, Fukui T. Factors related to biomedical research productivity in Asian countries. $J$ Epidemiol. 2001;11:199-201.

9. Rahman M. Biomedical publications in south Asian countries. Indian $J$ Public Health. 2003;47:72-4.

10. Kundra R, Srivastava D. Collaboration patterns among SAARC countries in the area of medicine: status and issues. Paper presented at: International workshop on Webometrics, Informetrics and Scientometrics \& Seventh COLLNET meeting; 10-12 May 2006; Nancy, France.

11. Alenzi FQB, Lotfy M, Nasif W, El-Shahat M, Abusini H, Alenazi M, et al. Biomedical research in the Middle Eastern countries: update and insight using SCImago Journal Rank indicator. $J$ Ayub Med Coll Abbottabad 2010;22:100-5.

12. Majumder MAA. Issues and Priorities of Medical Education Research in Asia. Ann Acad Med Singapore. 2004;33:257-63.

13. Rahman M, Fukui T. Biomedical publication Global profile and trend. Public Health. 2003;117:274-80. 